УДК 336.77:338.3:335.02:346.22

\title{
МЕХАНИЗМ ИСПОЛЬЗОВАНИЯ КРЕДИТНЫХ СРЕДСТВ В ГОСУДАРСТВЕННОМ ОБОРОННОМ ЗАКАЗЕ И ПРЕДЛОЖЕНИЯ ПО ЕГО СОВЕРШЕНСТВОВАНИЮ
}

\author{
Орловская Марина Анатольевна, \\ lunesmarina@mail.ru \\ Римская Ольга Николаевна, \\ olgarim@mail.ru
}

АО «Российские космические системы»,
Россия, 111250, г. Москва, ул. Авиамоторная, 53.

Орловская Марина Анатольевна, кандидат юридических наук, доцент, начальник отдела АО «Российские космические системы».

Римская Ольга Николаевна, кандидат экономических наук, доцент, начальник отдела АО «Российские космические системы».

\begin{abstract}
Актуальность. В оборонно-промышленный комплекс России входят около двух тысяч организаций и высокотехнологичных предприятий, расположенных в 64 субъектах Российской Федерации, в которых занято более 2 млн человек - рабочих, инженеров и ученых высочайшей квалификации. Несмотря на внушительный объем, рынок государственного оборонного заказа имеет специфические особенности как с экономической точки зрения, так и в области правового регулирования, особенно в вопросах кредитования предприятий и ценообразования на продукцию оборонного заказа. Целью статьи является разработка предложений по совершенствованию использования кредитных средств в государственном оборонном заказе. Одной из основных проблем, ведущих к несвоевременному заключению контрактов в России по государственному оборонному заказу, является ценообразование. В настоящий момент наблюдается полное отсутствие системы и алгоритмов управления ценами кооперации, что приводит к предсказуемому ухудшению финансового положения предприятий, работающих на оборону, и увеличению нагрузки на государственный бюджет. Методом сравнительного анализа нормативно-правовой базы и практики применения нормативных актов российскими предприятиями, работающими на оборонный заказ, выявлены проблемы в системе исполнения государственного заказа, в частности кредитовании предприятий и образовании цены на оборонную продукцию. Предложены механизмы совершенствования законодательной базы России по государственному оборонному заказу: законодательно закрепить разумную ставку кредитования и установить единый порядок образования цены на оборонную продукцию. Уделено внимание проблемам экономических и политических санкций против России, импортозамещения электронной компонентной базы, создания новых образцов военной техники, замещения кадров и привлечения молодых ученых и специалистов в производство.
\end{abstract}

Ключевые слова: Ценообразование продукции по государственному оборонному заказу, контрактная система, кредиты оборонных банков, законодательство по государственному оборонному заказу, государственный бюджет. 


\section{Введение}

Сегодня оборонно-промышленный комплекс (ОПК) России представляет собой совокупность научно-исследовательских институтов и промышленных предприятий, выполняющих разработку, производство, хранение, постановку на вооружение военной и специальной техники, амуниции, боеприпасов и т. п. преимущественно для государственных силовых структур, а также на экспорт. Россия производит все основные виды вооружений, включая технику сухопутных войск, авиационную и военно-морскую технику, средства противовоздушной обороны, ракеты, разведывательные спутники.

Доля России на мировом рынке вооружений составляет 25 \% и уступает только доле США (33 \%) [1]. Российские предприятия ОПК являются источником инновационных идей в развитии промышленного производства. Именно в продукции специального назначения аккумулируются основные технологические достижения нашей страны. Согласно имеющимся оценкам, на долю ОПК приходится более $70 \%$ всей научной продукции в России, в нем занято более 50 \% всех научных сотрудников. ОПК обеспечивает производство $70 \%$ всех средств связи, $60 \%$ сложной медицинской техники, 30 \% оборудования для ТЭК [2].

Бюджетные ассигнования по разделу «Национальная оборона» в 2018 г. составили 2771 784,6 млн руб., в 2019 г. - 2798 497,4 млн руб., а в 2020 г. запланировано 2807 994,3 млн руб. По отношению к объему ВВП соответствующего года доля расходов раздела «Национальная оборона» в 2018 г. - 2,8 \%, в 2019 г. - 2,7 \% и в 2020 г. $2,5 \%$. Доля в общем объеме расходов федерального бюджета по разделу «Национальная оборона» в 2018 и 2020 гг. по сравнению с 2017 г. (17,0 \%) уменьшится и составит $16,8 \%$, в 2019 г. увеличится и составит 17,1\% [3]. Несмотря на то, что на предприятия ОПК сегодня приходится всего около 5-6 \% промышленного производства, оборонный комплекс является составной частью национальной экономики и представляет собой наиболее наукоемкий сектор национальной экономики России.

Вместе с этим рынок ГОЗ имеет специфические черты [4]:

- это неконкурентный рынок, т. к. производителей продукции по государственному оборонному заказу (ГОЗ) в России немного;

- наличие единственного заказчика продукции ГОЗ - Министерство обороны, которое, собственно, определяет цены на продукцию;

- контрактная система ГОЗ, когда существуют единственные поставщики и контракты, заключаются по прямой закупке;

- основное законодательное отличие - это обязательное банковское сопровождение контракта (существуют разные типы банковского сопровождения);

- отсутствие механизмов регулирования цены на продукцию военного назначения.

Причин ухудшения финансового положения оборонных предприятий несколько. В первую очередь - упал объём ГОЗ. Из-за этого некоторые заводы планируют сократить рабочую неделю, максимально сохранив штат работников.

Другая причина - проблема ценообразования. Сегодня Минобороны единолично определяет стоимость военного продукта. Договорённости о цене являются предметом непрекращающихся споров между Минобороны и ОПК. Практика показывает, что механизмов ценорегулирования на товары военного назначения в России не существует, поэтому между заказчиком и исполнителями идут постоянные конфликты на тему того, что и сколько стоит. Заказчик не может много платить, а исполнители не могут работать себе в убыток. 
Исполнители недовольны тем, что жёсткие ценовые требования со стороны военных не учитывают постоянный рост цен на энергоносители, металл, услуги инфраструктурных монополий, растущие цены поставщиков комплектующих. Однако Минобороны, как единственный заказчик, имеет более сильные позиции, поэтому предприятия вынуждены идти на уступки.

Обеспечение исполнения обязательств по государственному контракту является одним из основных гражданско-правовых механизмов, позволяющих государственному заказчику превентивно реагировать на действия недобросовестных поставщиков (подрядчиков, исполнителей). Обеспечение исполнения обязательств создает дополнительную финансовую нагрузку на участников закупочных процедур в части расходов, связанных с оформлением банковской гарантии либо внесением денежных средств на счет заказчика.

Здесь в полной мере проявляется принципиальное отличие ГОЗ от других законов, регулирующих взаимоотношения на конкурентных рынках - это введение строгих условий банковского сопровождения [5].

\section{Существующая законодательная практика и предложения по совершенствованию для предприятий ОПК}

Исполнители ГОЗ обязаны работать в рамках закона № 275 [6] (далее - Федеральный закон № 275-Ф3) и вести раздельный учет ГОЗ, который существенно отличается от бухгалтерского и налогового учетов. Не все затраты, признаваемые в налоговом и бухгалтерском учетах, можно включать в цену продукции, поставляемой в рамках ГОЗ. Порядок определения затрат по договорам, заключенным после 29 апреля 2019 года, определен Приказом Минпромторга от 08.02.2019 г. № 334 [7], по ранее заключенным договорам - Приказом от 23.08.2006 г. № 200 [8].

Несоблюдение критерия экономической обоснованности и документального подтверждения является основанием для исключения затрат из цены продукции оборонного назначения, поставляемой по ГОЗ. Законом № 171-ФЗ расширен запрет на установление цен ГОЗ выше рыночных [9].

В Федеральном законе № 275-Ф3 недостаточно предусмотрены особые правила обеспечения исполнения обязательств по контракту, направленные на снижение дополнительной финансовой нагрузки на предприятия ОПК.

Одним из предложений является законодательное закрепление правил по обязательному включению в стоимость контракта затрат по оплате процентов по креди$m y$, привлекаемому для проведения опережающей закупки по ГОЗ.

На создание, испытание и отладки серийного выпуска любой оборонной продукции требуются годы. Их разработкой и производством занимается целая промышленная кооперация, включающая сотни конструкторских бюро, заводов и НИИ. Поэтапно синхронизировать деятельность предприятий ОПК с их финансированием по линии ГОЗ чрезвычайно сложно. Поэтому в целях качественного и своевременного выполнения ГОЗ по каждому мероприятию государственных программ всеми участниками цепи кооперации целесообразно использование метода математического моделирования сроков [10] с учетом длительности процессов исполнения ГОЗ и учета результатов моделирования.

В среднем кредитная нагрузка в стоимости заказа, исходя из правил бюджетных ассигнований по ГОЗ и в условиях действия Федерального закона № 275-ФЗ с учетом доли аванса, составляет 30-50 \% стоимости заказа. 
Такая кредитная нагрузка объективно формирует размер затрат по процентам по кредиту в размере 30-50 \% от валовой прибыли заказа, резко сокращая инвестиционную привлекательность и возможность эффективного развития промышленности, перераспределяя финансовые средства в банковский сектор.

Пункт 26 Приказа Минпромторга России № 334 предусматривает, что в статью калькуляции «Проценты по кредитам» включаются затраты на уплату процентов по кредитам в случае планируемой поставки продукции единственным поставщиком, в размере не более суммы, определенной с учетом ключевой ставки Центрального банка Российской Федерации, действующей на дату расчета цены плюс 1,5-процентного пункта, если не предусмотрено субсидирование данных затрат из федерального бюджета на момент формирования цены на изделие. Размер, срок и периодичность предоставления кредитной организацией кредита определяется организацией по согласованию с государственным заказчиком исходя из потребности организации в денежных средствах на производство продукции с учетом предложенного государственным заказчиком размера аванса. Однако статья калькуляции «Проценты по кредитам» используется при формировании цены вспомогательных работ и не включается в цену единицы продукции, что существенно уменьшает прибыль предприятий.

Аналогичное правило по учету кредитной нагрузки в стоимости заказа ранее было отражено в части II пункта 14 Приказа Минпромэнерго РФ № 200.

Нормативные акты разрешают вносить проценты по кредитам в состав затрат лишь отдельным категориям исполнителей. Попытки включения процентов по кредиту в состав затрат в настоящее время вызывает сложности из-за отсутствия прозрачности законодательства и проработанного механизма реализации такой возможности. Правоприменительная практика свидетельствует о единичных случаях фактического учета кредитной нагрузки в стоимости заказа. Более чем в $95 \%$ случаях - по причине непринятия данного вида затрат со стороны государственных заказчиков в стоимости заказа.

Расчет кредитной нагрузки в целях принятия в состав затрат возможно осуществлять только с даты подписания контракта. Тогда как значительная часть кредитной нагрузки связана с неурегулированностью методологического и нормативного инструмента формирования и сопоставления длительностей финансового и производственнотехнологического циклов выполнения ГОЗ.

Отсутствие специильного локального нормативного акта заказчика по вопросу порядка принятия и/или отказа в принятии экономически обоснованного размера затрат по кредитной нагрузке в стоимости заказа при выполнении ГОЗ ведет к высокому риску субъективизма при решении вопроса о включении размера затрат кредитной нагрузки в стоимость заказа.

Кроме того, не учитываются затраты на уплату процентов по кредитам в случае несвоевременного авансирования со стороны государственного заказчика, что является существенным условием общих принципов проведения государственных закупок в целом. Однако государственные контракты и, как следствие, договоры, заключаемые в цепочки их реализации, содержат условие, предусматривающее обязательство головного исполнителя (и соответственно других исполнителей) выполнять работы по договорам без соответствующего авансирования. Несвоевременность авансирования в процессе исполнения ГОЗ приводит к частым срывам исполнения государственных контрактов. Поступление аванса задерживается на период времени, отвлекаемый на согласование изменений и протоколов разногласий касательно сроков, объемов работ и порядка авансирования, на открытие отдельного или лицевого счета, утверждения сведе- 
ний о расходовании денежных средств у заказчика, их корректировку в связи с изменением законодательства и прочие процессуальные вопросы. До момента оформления полного пакета документов получение аванса невозможно, в связи с чем привлекаются собственные оборотные средства. По заказам Минобороны России даже при вовлечении собственных средств в предварительную закупку возникают сложности при финансировании и последующем принятии данных затрат со стороны военных представительств.

Еще одной из проблем является факт, что аванс в рамках исполнения ГОЗ перечисляется только на закупку материалов. Как показывает практика, объем авансирования даже в размере 30-60 \% недостаточен для финансирования выполнения заказа на протяжении всего жизненного цикла. Оплату труда, налогов, энергоносителей и прочие расходы организации производят за счет собственных средств, согласно законодательству РФ, они не могут быть оплачены после окончательного расчета заказчика. Привлечение кредитных ресурсов для финансирования таких затрат в принципе не рассматривается заказчиком как экономически обоснованное. В связи с чем необходимо в статью «затраты» включить возможность привлечения кредитных средств для выполнения объема работ, превышающего размер авансирования и необходимого для проведения обязательных оплат.

Согласно (пп. 12, 13 раздела ІІІ) Постановлению Правительства РФ № 1702 [11] привлечение временно свободных оборотных средств иных заказов на выполнение ГОЗ не возможно. Таким образом, отсутствует возможность временного вовлечения в оборотные средства размера прибыли каждого закрытого этапа у исполнителя, ввиду их временного «блокирования» на лицевых счетах (отдельных банковских счетах) исполнителей ГОЗ до завершения контракта в целом. Забирать прибыль поэтапно по мере сдачи этапа законодательно разрешено лишь головному исполнителю, следующий уровень кооперации может лишь попытаться прописать данное условие в договоре по согласованию с заказчиком, что чаще всего не получается.

Нет четкой формулировки порядка расчетов с использованием специального счета. В соответствии с пунктами 6, 7 части 1 и части 2 статьи 8 Федерального закона № 275-Ф3 головной исполнитель и исполнитель ГОЗ обязаны осуществлять расчеты по ГОЗ только с использованием отдельных счетов, открытых в уполномоченном банке. При этом положениями федерального закона также установлена обязанность по соблюдению режима использования отдельного счета участниками ГОЗ (статья 8 федерального закона). Поставщики товаров (работ, услуг) требуют заключения договоров с условием расчетов на расчетный счет, в связи с тем, что отсутствуют основания для квалификации расчетов участников ГОЗ с поставщиками без использования последними отдельных счетов в случаях, предусмотренных положениями федерального закона, как несоответствующих и (или) нарушающих действующее законодательство.

В связи с чем предлагается закрепить в законодательном и ведомственном порядке правила по обязательному включению в стоимость контракта затрат по оплате процентов по кредиту, привлекаемому для проведения опережающей закупки по ГОЗ, например законодательная проработка вопроса финансирования опережающей закупки. Источником финансирования опережающей закупки по ГОЗ может стать «Фонд пополнения оборотных средств» (как инструмент - аналог пополнения оборотных средств периода СССР). Финансирование из фонда предлагается производить централизовано главным распорядителем бюджетных средств, расчет срока финансирования средств производить как разницу между датой, организационно и технологически необходимой для начала финансирования жизненного цикла заказа и датой получения 
аванса или окончательного расчета по заказу. Размер (сумма) фондирования рекомендуется определять на базе расчета необходимого и достаточного объема опережающего финансирования закупок. Сумму фондирования предлагается рассматривать как возвратную и учитывать в уменьшении суммы аванса.

Необходимо на законодательном уровне принять решение о реализации механизма «Опережающзая закупка».

Для системного решения вопроса по опережающей закупке целесообразно проработать цифровую модель сетевого проектирования сквозного цикла исполнения ГОЗ, где предусмотреть, отразить и утвердить в нормативных правовых актах положения, регулирующие соответствие организационно-технологических и финансовых циклов всех этапов жизненного цикла заказов ГОЗ (от инициации, организации процесса разработки и создания продукции) с бюджетными периодами финансирования. Установить финансово-временные разрывы, создать регламент обоснования консолидированной опережающей закупки и проведения расчета дополнительных финансовых расходов организации в виде процентов по кредиту на нее.

Необходимо разрешить проведение консолидированной опережающей закупки исполнителем в целом по портфелю заказов с идентичными техническими требованиями к закупаемым товарам. Расходы на привлечение финансовых средств должны быть однозначно учтены и включены в расчет суммы запасов, подлежащих возмещению у головного исполнителя (исполнителя), в том числе из авансовых средств, получаемых в рамках подписанного государственного контракта (контракта).

Предлагается внести изменения (уточнить для однозначности применения всеми участниками процесса) в Приказ Минпромторга № 401 [12] в части обоснованности фактических расходов, связанных с формированием материальных запасов, необходимых для изготовления продукции ГОЗ с длительным технологическим циклом производства:

1. Пункт 5 изложить в редакции: «в состав запаса продукции, сырья, материалов, полуфабрикатов, комплектующих изделий, необходимого для изготовления продукции с длительным технологическим циклом производства в целях выполнения государственного оборонного заказа, включаются следующие виды ресурсов: материальные ресурсы, используемые в качестве сырья, материалов, полуфабрикатов и комплектующих изделий, специальное оборудование при производстве продукции. Средства, оплаченные соисполнителям в счет опережающей закупки с длительным технологическим циклом производства, но не полученные в дату подписания государственного контракта (контракта), включаются в состав запаса, но подлежат возмещению (компенсации) только на основании документов, свидетельствующих об их поступлении и оприходовании головным исполнителем (исполнителем).

2. В приложении в таблице «Сводный расчет...» в «порядке подтверждения исполнителем обоснованности фактических расходов, связанных с формированием запаса продукции, сырья, материалов, полуфабрикатов, комплектующих изделий, необходимого для изготовления продукции с длительным технологическим циклом производства в целях выполнения государственного оборонного заказа», утвержденном Приказом Минпромторга № 401, в части включения в текст следующего положения: «...строки «проценты по кредитам» в размере не более ставки рефинансирования Центрального банка Российской Федерации плюс 1,5-процентного пункта...» согласно п. 14 Порядка определения состава затрат на производство продукции оборонного назначения, поставляемой по государственному оборонному заказу, утвержден Приказом Минпромэнерго № 200 [13], такие затраты включаются в статью калькуляции «Прочие произ- 
водственные затраты» с учетом выполнения Правил ведения организациями, выполняющими государственный заказ за счет средств федерального бюджета, раздельного учета результатов финансово-экономической деятельности [14].

С целью обоснованности включения затрат по привлечению кредитных средств для проведения опережающей закупки внести изменения в локальные нормативные акты с учетом законодательства, регулирующего закупки для государственных компаний и государственного регулирования ГОЗ в части учета всех этапов жизненного цикла, исполнения государственного контракта, контрактов ГОЗ, регламентирующих процесс контрактации, технологической подготовки производства с учетом длительности процессов опережающей закупки и обеспечения по цепи кооперации создания продукции и длительности выпуска продукции.

В части отраслевого регулирования ценообразования продукции ГОЗ предлагается внести изменения в Приказ госкорпорации «Роскосмос» от 07.07.2017 г. № 231 [15], регулирующий порядок подтверждения исполнителем обоснованности фактических расходов, по формированию материальных запасов для изготовления продукции ГОЗ с длительным технологическим циклом производства, а именно:

1. Пункт 5 Порядка дополнить положениями следующего содержания: «В состав запаса включаются: сырье, материалы, полуфабрикаты и комплектующие изделия, необходимые для изготовления продукции с длительным технологическим циклом производства. Средства, оплаченные соисполнителям в счет опережающей закупки с длительным технологическим циклом производства, включаются в состав запаса и подлежат возмещению (компенсации) только на основании документов, свидетельствующих об их поступлении и оприходовании головным исполнителем (исполнителем).

2. Пункт 7 Порядка дополнить положениями следующего содержания: «Величина затрат на приобретение сырья, материалов, полуфабрикатов, комплектующих изделий, необходимых для изготовления продукции с длительным технологическим циклом производства, определяется исходя из размера сумм, уплачиваемых в соответствии с договором поставки (купли-продажи) поставщику (продавцу) и включения фактических затрат по статье ...проценты по кредитам в размере не более ставки рефинансирования Центрального банка Российской Федерации плюс 1,5-процентного пункта...». Согласно п. 14 Порядка определения состава затрат на производство продукции оборонного назначения (приказ Минпромторга № 200), такие затраты включаются в статью калькуляции «Прочие производственные затраты» при представлении необходимых первичных документов, подтверждающих выполнение Правил ведения организациями, выполняющими ГОЗ за счет средств федерального бюджета согласно Постановлению Правительства РФ № 47.

В связи с тем, что государственные заказчики зачастую вносят в условия контракта заведомо невыгодные положения в части авансирования головного исполнителя, предлагается внести изменения и дополнения в Закон о защите конкуренции [16].

Законом о защите конкуренции распространяется запрет на злоупотребление доминирующим положением на рынке приобретения комплектующих и запасных частей (рынок уникального товара).

Следовательно, данные головные исполнители и исполнители, доминирующие на рынке приобретения товара, с одной стороны, обязаны соблюдать правила конкуренции, установленные Законом о защите конкуренции, с другой - сталкиваются с поставщиками продукции по ГОЗ, которые навязывают невыгодные условия для заключения договора, например 100\%-я оплата, отсутствие требований по рекламационной работе (при этом возможна поставка некачественной, контрафактной продукции), и та- 
кие продавцы (поставщики) продукции по ГОЗ, являясь доминирующими, не придерживаются никаких требований, содержащихся в государственных контрактах.

Внести в подпункт 3 пункта 1 статьи 10 «Запрет на злоупотребление хозяйствующим субъектом доминирующим положением» Закона о защите конкуренции следующие дополнения: навязывание контрагенту условий договора, невыгодных для него или не относящихся к предмету договора (экономически или технологически не обоснованные и (или) прямо не предусмотренные федеральными законами, нормативными правовыми актами Президента Российской Федерации, нормативными правовыми актами Правительства Российской Федерации, нормативными правовыми актами уполномоченных федеральных органов исполнительной власти или судебными актами требования о передаче финансовых средств, иного имущества, в том числе имущественных прав, а также согласие заключить договор при условии внесения в него положений относительно товара, в котором контрагент не заинтересован, и другие требования), а также навязывание контрагенту условий или несогласие на включение условий, предусмотренных государственным контрактом, заключённым в целях обеспечения государственного оборонного заказа, а также отказ от заключения договоров в целях обеспечения государственного оборонного заказа.

Внесение жестких условий в государственные контракты, предусматривающих возмещение затрат на уплату процентов по кредитам, привлекаемым головными исполнителями для целей выполнения ГОЗ следующего содержания: отсутствие авансирования не является основанием для невыполнения работ. Заказчик обязан возместить затраты на уплату процентов по кредитам, привлекаемым головными исполнителями для целей выполнения ГОЗ.

Кроме того, в части комплексной проработки вопроса защиты прав и законных интересов головного исполнителя и других исполнителей в рамках ГОЗ предлагается внести изменения и дополнения в Постановление Правительства РФ № 1275 [17].

Дополнить подпунктом «з» пункт 10 Положения о примерных условиях государственных контрактов по государственному оборонному заказу следующего содержания:

«10. В государственном контракте устанавливаются права и обязанности государственного заказчика, включая:

3. обязанность государственного заказчика по возмещению затрат на уплату процентов по кредитам, привлекаемым головными исполнителями для целей выполнения государственного оборонного заказа».

Изложить первое предложение пункта 12 Положения о примерных условиях государственных контрактов по ГОЗ в следующей редакции:

«12. В государственном контракте устанавливаются цена контракта; вид цены, а также условия и порядок ее формирования (расчета); авансирования работ; осуществления взаиморасчетов и возмещение затрат на уплату процентов по кредитам, привлекаемым головными исполнителями (исполнителями) для целей выполнения государственного оборонного заказа».

Дополнить подпунктом «л» Положения о примерных условиях государственных контрактов по ГОЗ в следующей редакции: «13. Независимо от способа определения головного исполнителя и соответствующего ему порядка формирования цены в государственном контракте кроме цены государственного контракта указываются: л) условия, при которых цена государственного контракта может быть увеличена без изменения предусмотренных им количества и качества поставляемой продукции на сумму за- 
трат на уплату процентов по кредитам, привлекаемым головными исполнителями (исполнителями) для целей выполнения государственного оборонного заказа».

Кроме того, следует отметить, что в настоящее время сохраняется ответственность за нарушение правил ведения раздельного учета результатов финансовохозяйственной деятельности.

Установлено, что утвержденные Постановлением Правительства РФ № 47 правила ведения раздельного учета результатов финансово-хозяйственной деятельности не применяются организациями при использовании полученных ими на основании государственных контрактов средств, подлежащих казначейскому сопровождению в соответствии с бюджетным законодательством РФ. Однако Минфин России и Казначейство считают, что обязанность вести раздельный учет следует из Закона о бюджете [18] и подзаконных актов. При ведении раздельного учета нужно руководствоваться порядком, утвержденным Минфином и Казначейством [19].

В соответствии с частью 1 статьи 15.37 Кодекса об административных правонарушениях РФ [19] неисполнение головным исполнителем (исполнителем) по ГОЗ требования о ведении раздельного учета результатов финансово-хозяйственной деятельности влечет наложение административного штрафа на должностных лиц в размере от двадцати тысяч до пятидесяти тысяч рублей; на юридических лиц - от трехсот тысяч до пятисот тысяч рублей.

Следовательно, обязанность по ведению головным исполнителем (исполнителем) по ГОЗ раздельного учета результатов финансово-хозяйственной деятельности дублирует функции казначейства. В связи с чем предлагается внести изменения в Кодекс об административных правонарушениях от 30.12.2001 г. № 195-Ф3 и дополнить пункт 1 статьи 15.37 словами «за исключением случаев, если денежные средства подлежат казначейскому сопровождению после слов “финансово-хозяйственной деятельности””.

\section{Заключение}

Рыночная конкуренция обеспечивает эффективность, а целевое кредитование призвано финансировать реализацию важнейших национальных инвестиционных проектов [20]. Главная особенность функционирования российского ОПК состоит в том, что реального, конкурентного рынка в ОПК не существует. Отношения внутри кооперации - это жесткое администрирование и государственное регулирование.

Слабость и нестабильность российской экономики, следование мировому тренду увеличения доли услуг, а не производства, означает отсроченное поглощение или разорение российских высокотехнологичных предприятий, в том числе в отрасли машиностроения. Ухудшение экономического состояния в стране в условиях продолжающейся экономической рецессии неизменно влечет сокращение налоговых поступлений и, соответственно, бюджетных расходов. Имеет место неэффективная-государственная политика по отношению к предприятиям ОПК, треть которых уже является банкротами, а треть страдает от высокой кредитной нагрузки. Ведь 9 крупных российских банков, определенных законом для выдачи оборонных кредитов, финансируют предприятия ОПК по ставке 20-30 \% годовых. Таких ставок для бизнеса не существует нигде в мире. Создается впечатление, что ОПК работает только на банки, а не на военные нужды страны.

В июле 2019 г. объем кредитов предприятиям ОПК составил более 2 трлн руб., заявил курирующий эту сферу вице-премьер Юрий Борисов в рамках выставки «Иннопром» [21]. Он добавил, что из-за большой кредитной нагрузки предприятия «живут впроголодь», и предложил списать им 600-700 млрд руб. кредитов. Следует отметить, что вклад в создавшееся бедственное положение внес государственный заказчик - 
Минобороны РФ за счет несвоевременной оплаты работ по ГОЗ и несвоевременного размещения самого госзаказа, что вылилось в нескончаемые судебные процессы.

Только для уплаты процентов по кредитам предприятия ОПК в 2018 г. потратили около 135 млрд руб., что соответствует плановой прибыли предприятий ОПК [22].

Государство, являясь гарантом, фактически оплачивает из государственного бюджета банкам кредиты предприятий ОПК вместо того, чтобы законодательно закрепить разумную ставку кредитования и установить единый порядок образования цены на продукцию, выполняемую по ГОЗ.

Кроме перечисленных проблем в ОПК есть и другие, стоящие в очереди и требующие решения: старение и замещение кадров; привлечение и закрепление молодых ученых и разработчиков; необходимость использовать передовые технологии на производстве и на этапе создания продукции; подготовка управленческого резерва менеджеров для управления российскими предприятиями по современным стандартам в российских университетах. Совершенно очевидно, что дорогостоящие программы MBA, которые в России не имеют образовательного стандарта, не способны подготовить эффективного в российских реалиях менеджера, нацеленного не на продажу, а на производство продукции [23].

К существующим внутренним проблемам ОПК нужно прибавить внешнюю - установление против России экономических и политических санкций коалицией западных стран. Санкции являются большим ударом по сложившимся годами отношениям с зарубежными партнерами, приводят к финансовым потерям и сложностям во взаимодействии с обеих сторон. Развал Советского союза и промышленности странучастников объединения уже сказался на российском ОПК. Новые отношения с партнерами из стран СНГ складываются непросто. Негативные последствия от санкций, если они не будут усилены, но и не будут отменены, в большей степени могут сказаться на российской экономике «накопленным эффектом» в ближайшее время, как считают российские экономисты.

Вопрос импортозамещения комплектующих для продукции ГОЗ, которые предполагается производить на основе мощностей предприятий ОПК, до сих пор не решен, хотя некоторые сдвиги в этом направлении наблюдаются.

Президент В. Путин поставил вопрос о необходимости разработки механизма регулирования и производства высокотехнологической продукции военного назначения, который заинтересует предприятия не только в ее создании, но и на этапе опытноконструкторской разработки в создании новых образцов военной техники, не имеющих аналогов за рубежом.

Предлагаемые авторами данной статьи меры по урегулированию законодательства не являются исчерпывающими, однако принятие поправок существенно облегчит предприятиям кооперации выполнение ГО3, обеспечит четкий порядок взаимодействия между заказчиком и исполнителями контракта ГОЗ, а также предотвратит судебные разбирательства по данному вопросу.

\section{СПИСОК ЛИТЕРАТУРЫ}

1. SIPRI представил рейтинг 100 крупнейших мировых производителей оружия (данные по российским предприятиям ОПК). URL: http://www.armstrade.org/includes/periodics/news/2019/1209/144055728/detail.shtml (дата обращения 11.11.2019).

2. Цветков В.А. Оборонно-промышленный комплекс России: Проблемы и перспективы развития // Сборник докладов Второй конференции «Экономический потенциал промышленности на службе оборонно-промышленного комплекса» 9-10 ноября 2016 г. Москва, Финансовый университет при Правительстве РФ. - М., 2016. - С. 7-9. 
3. Расходы РФ на национальную оборону в 2018 году составят более 2,77 трлн рублей. URL: https://tass.ru/ekonomika/4604078 (дата обращения 21.10.2019).

4. Беляева О.А. Гособоронзаказ: законодательный нонсенс. URL: https://www.bicotender.ru/interview/ interview-gosoboronzakaz-zakonodatelniy-nonsens.html (дата обращения 21.10.2019).

5. Постатейное сравнение приказов 200 и 334. URL: http://www.krikunov.ru/wp-content/uploads/ 2019/06/200_334.pdf (дата обращения 12.11.2019).

6. О государственном оборонном заказе: федер. закон от 29 декабря 2012 года № 275. URL: http://www.consultant.ru/document/cons_doc_LAW_140175/ (дата обращения 21.10.2019).

7. Об утверждении порядка определения состава затрат, включаемых в цену продукции, поставляемой в рамках государственного оборонного заказа: приказ Министерства промышленности и торговли № 334 от 8 февраля 2019 года. URL: https://rulaws.ru/acts/Prikaz-Minpromtorga-Rossii-ot-08.02.2019-N334/ (дата обращения 14.11.2019).

8. Об утверждении Порядка определения состава затрат на производство продукции оборонного назначения, поставляемой по государственному оборонному заказу: приказ Министерства промышленности и энергетики России от 23 августа 2006 года № 200 (ред. от 07.11.2013). URL: https://normativ.kontur.ru/document?moduleId=1\&documentId=246818 (дата обращения 14.11.2019).

9. О внесении изменений в Кодекс Российской Федерации об административных правонарушениях и приостановлении действия отдельных положений статьи 14.5 Кодекса Российской Федерации об административных правонарушениях: федер. закон от 3 июля 2019 года № 171-Ф3. URL: http://www.consultant.ru/document/cons_doc_LAW_328164/ (дата обращения 14.11.2019).

10. Йескомб Э. Принципы проектного финансирования. - М.: Альпина Паблишер, 2015. - 408 с.

11. Об утверждении Правил казначейского сопровождения средств государственного оборонного заказа в валюте Российской Федерации в случаях, предусмотренных Федеральным законом «О федеральном бюджете на 2019 год и на плановый период 2020 и 2021 годов»: постановление Правительства РФ от 28 декабря 2018 года № 1702. URL: http://base.garant.ru/72141904/ (дата обращения 14.11.2019).

12. Об утверждении порядка подтверждения исполнителем обоснованности фактических расходов, связанных с формированием запаса продукции, сырья, материалов, полуфабрикатов, комплектующих изделий, необходимого для изготовления продукции с длительным технологическим циклом производства в целях выполнения государственного оборонного заказа: приказ Министерства промышленности и торговли от 13 февраля 2017 года № 401. URL: https://normativ.kontur.ru/document?moduleId=1\&documentId=292827 (дата обращения 14.11.2019).

13. Об утверждении Порядка определения состава затрат на производство продукции оборонного назначения, поставляемой по государственному оборонному заказу: приказ Минпромэнерго России от 23.08.2006 № 200 (ред. от 07.11.2013). http://www.consultant.ru/document/cons_doc_LAW_65032/ (дата обращения 14.11.2019).

14. О Правилах ведения организациями, выполняющими государственный заказ за счет средств федерального бюджета, раздельного учета результатов финансово-хозяйственной деятельности: постановление Правительства РФ от 19 января 1998 года № 47 (ред. от 22.06.2019). URL: http://www.consultant.ru/document/cons_doc_LAW_17542/ (дата обращения 14.11.2019).

15. Об утверждении Порядка подтверждения исполнителем обоснованности фактических расходов, связанных с формированием запаса продукции, сырья, материалов, полуфабрикатов, комплектующих изделий, необходимого для изготовления продукции с длительным технологическим циклом производства в целях выполнения государственного оборонного заказа: приказ Госкорпорации «Роскосмос» от 7 июля 2017 года № 231. URL: http://www.consultant.ru/document/cons_doc_LAW_282371/ (дата обращения 14.11.2019).

16. О защите конкуренции: федер. закон от 26 июля 2006 года № 135-Ф3. URL: http://www.consultant.ru/document/cons_doc_LAW_61763/ (дата обращения 14.11.2019).

17. О примерных условиях государственных контрактов (контрактов) по государственному оборонному заказу: постановление Правительства РФ от 26 декабря 2013 г. № 1275. URL: http://government.ru/docs/9523/ (дата обращения 14.11.2019).

18. О федеральном бюджете на 2019 год и на плановый период 2020 и 2021 годов: федер. закон от 29 ноября 2018 № 459-Ф3 (последняя редакция). URL: http://www.consultant.ru/document/ cons_doc_LAW_312362/ (дата обращения 14.11.2019).

19. О ведении юридическими лицами раздельного учета результатов финансово-хозяйственной деятельности при казначейском сопровождении целевых средств: письмо Министерства финансов России № 09-01-05/11480, Казначейства России № 07-04-05/22-3551 от 21 декабря 2019. URL: https://rulaws.ru/acts/Pismo-Minfina-Rossii-N-09-01-05_11480,-Kaznacheystva-Rossii-N-07-04-05_223551-ot-21.02.2019/ (дата обращения 14.11.2019). 
20. Кодекс Российской Федерации об административных правонарушениях от 30 декабря 2001 года № 195-Ф3 (ред. от 27 декабря 2019 года). URL: http://www.consultant.ru/document/cons_doc_LAW_34661/ (дата обращения 14.11.2019).

21. Глазьев С.Ю. Методология опережающего развития экономики: как решить поставленную Президентом России задачу рывка в экономическом развитии // Труды Вольного экономического общества России. - 2019. - T. 218. - C. 124-132. URL: https://www.usue.ru/public/files/2019/September/ veo_218_maef.pdf (дата обращения 14.11.2019).

22. Почему российскому ОПК потребовалось списание Р700 млрд кредитов. URL: https://www.rbc.ru/economics/08/07/2019/5d2320289a7947771c7d26еa (дата обращения 14.11.2019).

23. Бетелин В.Б. Модель реализации Государственной программы вооружения - основа реализации национальных проектов // Научные труды Вольного экономического общества России. - 2019. - Т. 218. - C.116-123.

Поступила 20.11.2019 2. 


\title{
MECHANISM FOR USING CREDIT FUNDS IN DEFENSE PROCUREMENT AND PROPOSALS FOR ITS IMPROVEMENT
}

\author{
Marina A. Orlovskaya, \\ lunesmarina@mail.ru \\ Olga N. Rimskaya, \\ olgarim@mail.ru \\ Russian Space Systems JSC, \\ 53, Aviamotornaya street, Moscow, 111250, Russia.
}

\begin{abstract}
Marina A. Orlovskaya, Cand. Sc., associate professor, head of department, Russian Space Systems JSC.
Olga N. Rimskaya, Cand. Sc., associate professor, head of department, Russian Space Systems JSC.
\end{abstract}

Relevance. The military-industrial complex of Russia includes about 2 thousand organizations and high-tech enterprises located in 64 constituent entities of the Russian Federation, which employ more than 2 million people: workers, engineers and scientists of the highest qualification. Despite the impressive volume, the state defense procurement market has peculiar features both from an economic and legal point of view, especially in matters of lending to enterprises and pricing for defense products. The aim of this article is to develop proposals for improving the use of credit in the state defense procurement. One of the main problems leading to the untimely fulfillment of state defense procurement contracts in Russia is pricing. Currently, there is a complete lack of organization and algorithms in the cooperation pricing, which predictably leads to deterioration in the financial situation of enterprises working for defense and growing burden on the state budget. Using the method of comparative analysis of the regulatory framework and the experience of applying regulatory acts by Russian enterprises working for defense procurement, we identified the problem areas in the mechanism for executing state orders, in particular, lending to enterprises and raising the price of defense products. The authors have proposed the mechanisms for improving the Russian legislative base for state defense procurement: to legislatively establish a reasonable lending rate and establish a unified procedure for pricing defense products. The authors address the problems of economic and political sanctions against Russia, import substitution of electronic components, creation of new models of military equipment, replacement of personnel and the involvement of young scientists and specialists in production.

Key words: State defense procurement pricing, contract system, loans from defense banks, legislation on state defense orders, state budget.

\section{REFERENCES}

1. SIPRI predstavil reyting 100 krupneyshikh mirovykh proizvoditeley oruzhiya (dannye po rossiyskim predpriyatiyam OPK) [SIPRI presented a rating of the 100 largest world arms manufacturers (data on Russian defense industry enterprises]. Available at: http://www.armstrade.org/includes/periodics/news/ 2019/1209/144055728/detail.shtml (accessed 11 November 2019).

2. Tsvetkov V.A. Oboronno-promyshlenny kompleks Rossii: problemy i perspektivy razvitiya [The militaryindustrial complex of Russia: problems and development prospects]. Sbornik dokladov Vtoroy konferentsii. Ekonomicheskiy potentsial promyshlennosti na sluzhbe oboronno-promyshlennogo kompleksa [Collection of reports of the Second Conference. Economic Potential of Industry in the Service of the MilitaryIndustrial Complex]. Russia, Moscow, November 9-10, 2016. Moscow, Finansovy universitet pri Pravitelstve RF, 2016. pp. 7-9. 
3. Raskhody RF na natsionalnuyu oboronu v 2018 godu sostavyat bolee 2,77 trln rubley [Spending of the Russian Federation on national defense in 2018 will amount to more than 2.77 trillion rubles]. Available at: https://tass.ru/ekonomika/4604078 (accessed 21 October 2019).

4. Belyaeva O.A. Gosoboronzakaz: zakonodatelny nonsens [State defense order: legislative nonsense]. Available at: https://www.bicotender.ru/interview/interview-gosoboronzakaz-zakonodatelniy-nonsens.html (accessed 21October 2019).

5. Postateynoe sravnenie prikazov 200 i 334 [An article-by-article comparison of orders 200 and 334]. Available at: http://www.krikunov.ru/wp-content/uploads/2019/06/200_334.pdf (accessed 12 November 2019).

6. O gosudarstvennom oboronnom zakaze [On the state defense order]. Federalny zakon ot 29 dekabrya 12 goda no. 275 [Federal Act No. 275 of 29 December 2012]. Available at: http://www.consultant.ru/ document/cons_doc_LAW_140175/(accessed 21 October 2019)

7. Ob utverzhdenii poryadka opredeleniya sostava zatrat, vklyuchayemykh $v$ tsenu produktsii, postavlyaemoy $v$ ramkakh gosudarstvennogo oboronnogo zakaza [On the approval of the procedure for determining the composition of costs included in the price of products supplied under the state defense order]. Prikaz Ministerstva promyshlennosti i torgovli ot 8 fevralya 2019 no. 334 (vstupil v silu s 30.04.2019) [Order of the Ministry of Industry and Trade No. 334 dated 08.02.2019. (entered into force on April 30, 2019)]. Available at: https://rulaws.ru/acts/Prikaz-Minpromtorga-Rossii-ot-08.02.2019-N-334/ (accessed 14 November 2019).

8. Ob utverzhdenii Poryadka opredeleniya sostava zatrat na proizvodstvo produktsii oboronnogo naznacheniya, postavlyaemoy po gosudarstvennomu oboronnomu zakazu [On the approval of the procedure for determining the composition of costs for the production of defense products supplied by the state defense order]. Prikaz Ministerstva promyshlennosti i energetiki Rossii ot 23 avgusta 2006 no. 200 (red. ot 07.11.2013). [Decree of the Ministry of Industry and Energy of the Russian Federation No. 200 of $23 \mathrm{Au}-$ gust 2006 (in force as of 07 November 2013). Available at: https://normativ.kontur.ru/document?moduleId= 1\&documentId=246818 (accessed 14 November 2019).

9. O vnesenii izmeneniy $v$ Kodeks Rossiyskoy Federatsii ob administrativnykh pravonarusheniyakh $i$ priostanovlenii deystviya otdelnykh polozheniy stati 14.5 Kodeksa Rossiyskoy Federatsii ob administrativnykh pravonarusheniyakh [On introducing amendments to the Code of the Russian Federation on Administrative Offenses and suspension of certain provisions of Article 14.5 of the Code of the Russian Federation on Administrative Offenses]. Federalny zakon ot 3 iyulya 2019 goda no. 171-FZ [Law dated 03.07.2019 N 171-FL]. Available at: http://www.consultant.ru/document/cons_doc_LAW_328164/ (accessed 14 November 2019).

10. Yeskomb E. Printsipy proektnogo finansirovaniya [Principles of project finance]. Moscow, Alpina Publisher, 2015. $408 \mathrm{p}$.

11. Ob utverzhdenii Pravil kaznacheyskogo soprovozhdeniya sredstv gosudarstvennogo oboronnogo zakaza $v$ valyute Rossiyskoy Federatsii v sluchayakh, predusmotrennykh Federalnym zakonom «O federalnom byudzhete na 2019 god i na planovy period 2020 i 2021 godov»" [On the approval of the Rules for treasury support of state defense order funds in the currency of the Russian Federation in cases provided for by the Federal Law «On the Federal Budget for 2019 and for the Planning Period 2020 and 2021»]. Postanovlenie Pravitelstva RF ot 28 dekabrya 2018 goda no. 1702 [Decree of the Government of the Russian Federation dated December 28, 2018 No. 1702.]. Available at: http://base.garant.ru/72141904/ (accessed 14 November 2019).

12. Ob utverzhdenii poryadka podtverzhdeniya ispolnitelem obosnovannosti fakticheskikh raskhodov, svyazannykh s formirovaniem zapasa produktsii, syrya, materialov, polufabrikatov, komplektuyushchikh izdeliy, neobkhodimogo dlya izgotovleniya produktsii s dlitelnym tekhnologicheskim tsiklom proizvodstva $v$ tselyakh vypolneniya gosudarstvennogo oboronnogo zakaza [On approval of the contractor's confirmation of the validity of actual costs associated with the formation of a stock of products, raw materials, materials, semi-finished products, components necessary for the manufacture of products with a long production cycle in order to fulfill the state defense order]. Prikaz Ministerstva promyshlennosti i torgovli ot 13 fevralya 2017 goda no. 401 [Order of the Ministry of Industry and Trade of February 13, 2017 No. 401.]. Available at: https://normativ.kontur.ru/document?moduleId=1\&documentId=292827 (accessed 14 November 2019).

13. Ob utverzhdenii Poryadka opredeleniya sostava zatrat na proizvodstvo produktsii oboronnogo naznacheniya, postavlyaemoy po gosudarstvennomu oboronnomu zakazu [Decree of the Ministry of Industry and Energy of the Russian Federation No. 200 of 23 August 2006 (in force as of 07 November 2013)]. Prikaz Minpromenergo Rossii ot 23.08.2006 No. 200 (red. ot 07.11.2013). [On the approval of the procedure for determining the composition of costs for the production of defense products supplied by the state defense order]. Available at: http://www.consultant.ru/document/cons_doc_LAW_65032/ (accessed 14 November 2019). 
14. O Pravilakh vedeniya organizatsiyami, vypolnyayushchimi gosudarstvenny zakaz za schet sredstv federalnogo byudzheta, razdelnogo ucheta rezultatov finansovo-khozyaystvennoy deyatelnosti [On the Rules for maintaining organizations performing the state order at the expense of the federal budget, separate accounting of the results of financial and economic activities]. Postanovlenie Pravitelstva RF ot 19 yanvarya 1998 no. 47 (red. ot 22.06.2019). [Decree of the Government of the Russian Federation of January 19, $1998 \mathrm{~N} 47$ (as amended on June 22, 2019)]. Available at: http://www.consultant.ru/document/cons_doc_LAW_17542/(accessed 14 November 2019).

15. Ob utverzhdenii Poryadka podtverzhdeniya ispolnitelem obosnovannosti fakticheskikh raskhodov, svyazannykh s formirovaniem zapasa produktsii, syrya, materialov, polufabrikatov, komplektuyushchikh izdeliy, neobkhodimogo dlya izgotovleniya produktsii s dlitelnym tekhnologicheskim tsiklom proizvodstva $v$ tselyakh vypolneniya gosudarstvennogo oboronnogo zakaza [On approval of the Procedure for confirmation by the contractor of the validity of actual costs associated with the formation of a stock of products, raw materials, materials, semi-finished products, components necessary for the manufacture of products with a long production cycle in order to fulfill the state defense order]. Prikaz Goskorporatsii «Roskosmos» ot 7 iyulya 2017 no. 231 [Order of the State Corporation «Roscosmos» dated 07.07.2017 N 231]. Available at: http://www.consultant.ru/document/cons_doc_LAW_282371/(accessed 14 November 2019).

16. $O$ zashchite konkurentsii [On competition protection]. Federalny zakon ot 26 iyulya 2006 no. 135-FZ. [Federal Law of July 26, 2006 No. 135-FL]. Available at: http://www.consultant.ru/document/ cons_doc_LAW_61763/ (accessed 14 November 2019).

17. O primernykh usloviyakh gosudarstvennykh kontraktov (kontraktov) po gosudarstvennomu oboronnomu zakazu [On the approximate conditions of state contracts (contracts) for the state defense order]. Postanovleniye Pravitelstva RF ot 26 dekabrya 2013 no. 1275 [Decree of the Government of the Russian Federation of 12.26.2013 No. 1275]. Available at: http://government.ru/docs/9523/ (accessed 14 November 2019).

18. O federalnom byudzhete na 2019 god i na planovy period 2020 i 2021 godov [On the federal budget for 2019 and for the planning period 2020 and 2021]. Federalnyy zakon ot 29.11.2018 N 459-FZ (poslednyaya redaktsiya) [Federal Law of 29.11.2018 N 459-FL (latest revision)]. Available at: http://www.consultant.ru/document/cons_doc_LAW_312362/(accessed 14 November 2019).

19. O vedenii yuridicheskimi litsami razdelnogo ucheta rezultatov finansovo-khozyaystvennoy deyatelnosti pri kaznacheyskom soprovozhdenii tselevykh sredstv [On the maintenance by legal entities of separate accounting of the results of financial and economic activities with treasury support of target funds]. Pismo Ministerstva finansov Rossii no. 09-01-05/11480, Kaznacheystva Rossii no. 07-04-05/22-3551 ot 21.02.2019 [Letter of the Ministry of Finance of Russia N 09-01-05 / 11480, the Treasury of Russia N 0704-05 / 22-3551 of 02.21.2019]. Available at: https://rulaws.ru/acts/Pismo-Minfina-Rossii-N-09-0105_11480,-Kaznacheystva-Rossii-N-07-04-05_22-3551-ot-21.02.2019/(accessed 14 November 2019).

20. Kodeks Rossiyskoy Federatsii ob administrativnykh pravonarusheniyakh ot 30 dekabrya 2001 goda no. 195-FZ (red. ot 27 dekabrya 2019) [Code of the Russian Federation on Administrative Offenses of 30 December 2001 No. 195-FL (in force as of 27 December 2019)]. Available at: http://www.consultant.ru/document/cons_doc_LAW_34661/(accessed 14 November 2019).

21. Glazyev S.Yu. A methodology for accelerated economic growth: achieving the economic breakthrough goal set by the President of Russia. Scientific works of the free economic society of Russia, 2019, vol. 218, pp. 124-132. In Rus. Available at: https://www.usue.ru/public/files/2019/September/veo_218_maef.pdf (accessed 14 November 2019).

22. Pochemu rossiyskomu OPK potrebovalos spisanie 7700 mlrd kreditov [Why did the Russian defense industry need to write off $\$ 700$ billion of loans]. Available at:

23. https://www.rbc.ru/economics/08/07/2019/5d2320289a7947771c7d26ea (accessed 14 November 2019).

24. Betelin V.B. The model of implementation of the State armament program is the basis for the implementation of national projects. Scientific works of the free economic society of Russia, 2019, vol. 218, pp. 116123. In Rus. Available at: https://www.usue.ru/public/files/2019/September/veo_218_maef.pdf (accessed 14 November 2019).

Received: 20 November 2019. 